\title{
Assessment of Immunization to Hepatitis B Vaccine among Children under Five Years in Rural Areas of Taiz, Yemen
}

\author{
Fuad A. A. Alssamei, ${ }^{1}$ Najla A. Al-Sonboli, ${ }^{2,3}$ Fawzi A. Alkumaim, ${ }^{4}$ Nader S. Alsayaad, \\ Mohammed S. Al-Ahdal, ${ }^{4}$ Tarig B. Higazi, ${ }^{5}$ and Atif A. Elagib ${ }^{6}$ \\ ${ }^{1}$ Microbiology and Immunology Departments, Military Hospital, Sana'a, Yemen \\ ${ }^{2}$ Pediatrics Department, Faculty of Medicine and Health Sciences, Sana'a University, Sana'a, Yemen \\ ${ }^{3}$ Pediatrics Department, Al-Sabeen Maternity and Child Hospital, Sana'a, Yemen \\ ${ }^{4}$ Virology and Serology Department, Military Hospital, Sana'a, Yemen \\ ${ }^{5}$ Department of Biological Sciences, Ohio University Zanesville, Zanesville, OH, USA \\ ${ }^{6}$ National Center for Research, Khartoum, Sudan \\ Correspondence should be addressed to Fuad A. A. Alssamei; fuadsamiy@yahoo.com
}

Received 18 November 2016; Accepted 22 January 2017; Published 6 March 2017

Academic Editor: Man-Fung Yuen

Copyright (C) 2017 Fuad A. A. Alssamei et al. This is an open access article distributed under the Creative Commons Attribution License, which permits unrestricted use, distribution, and reproduction in any medium, provided the original work is properly cited.

Background. Hepatitis B virus (HBV) infection poses a major health problem worldwide. approximately 1 million deaths annually due to cirrhosis and hepatocellular carcinoma. Objectives. This study was conducted to determine the coverage rate of $\mathrm{HBV}$ vaccine and assess the vaccine protective response among children under five years old in rural areas of Yemen. Methods. A cross-sectional study was conducted from January to December 2015 in four districts of countryside Yemen. The target population was children aged from 6 to 59 months. 227 children were enrolled in the study. Questionnaire was used to collect of data. Serum samples were tested for anti-HBs antibodies by enzyme linked immunosorbent assay (ELISA). Anti-HBs level $\geq 10 \mathrm{IU} / \mathrm{L}$ was considered a protective response to the vaccine. Results. The coverage rate of HBV vaccine among children was $87.3 \%$. A total of 143 (72.2\%) children responded to the vaccine with anti-HBs level $\geq 10 \mathrm{IU} / \mathrm{L}$, while $55(27.8 \%)$ of the children had nonprotective anti-HBs levels of $<10 \mathrm{IU} / \mathrm{L}(P=0.003)$. Conclusion. This study revealed a good coverage rate of HBV vaccine in rural areas but the protective rate against $\mathrm{HBV}$ infection was moderate. A considerable proportion of vaccinated children should be considered for either revaccination or booster doses.

\section{Introduction}

A major cause of morbidity and mortality in children are infectious diseases, including hepatitis B [1]. Hepatitis B virus (HBV) infection remains a global challenge, with one-third of the world's population having serological evidence of current or previous infection. Around 400 million people worldwide are chronically infected with HBV that leads to approximately 1 million deaths annually due to cirrhosis and hepatocellular carcinoma [2]. Primary prevention by immunization remains the most effective way to control the spread of HBV especially in developing country [3]. However, it is estimated that every year at least 27 million children worldwide do not receive the basic package of immunizations. About $25 \%$ of children under five years' mortality is due to infectious diseases preventable by vaccine $[4,5]$. Previous surveys carried out in Yemen showed high prevalence of hepatitis B surface antigen (HBsAg) ranging from 8 to $20 \%$ [6] and up to $50 \%$ in the capital Sana'a [7]. Other studies in Yemen reported HBsAg overall prevalence of $10.5 \%$ in Sanaa, $4.8 \%$ in Aden, $5.6 \%$ in Hajah, $26.3 \%$ in Soqotra [8], and $16.9 \%$ in Taiz [9] governorate during the period between 2000 and 2005. It has been reported that chronic infection generally develops among $90 \%$ of newborns, $29-40 \%$ of children ( $1-5$ years old), and $5-10 \%$ of adults [10].

With the availability of HBV vaccine since 1982, the decline in the incidence of HBV infection and associated morbidity and mortality has been reported in Taiwan and the 
United States [11, 12]. In 1998, the World Health Organization (WHO) recommended the inclusion of $\mathrm{HBV}$ vaccine in the national immunization program of Yemen particularly among neonates, where vertical transmission is common, regardless of the prevalence of circulating HBsAg [13]. Despite a remarkable success in immunization coverage in Yemen, there are still areas of low coverage and a gap still exists between urban and rural areas. Nearly 13.5 million (54\%) Yemenite live below the poverty line and the majority of them $(66-87 \%)$ live in rural areas [14, 15]. Factors associated with decreased immune response to $\mathrm{HBV}$ vaccine include increasing age, gender, obesity, nutritional status, smoking, and genetic factors $[16,17]$. Poverty, socioeconomic status, lack of education, and weak health systems in rural areas in Yemen are interrelated factors that influence growth of children, which in turn affect their immune system [14] and response to vaccines.

In general, three doses of HBV vaccine provide a safe level of protection in $95 \%$ of healthy infants and healthy children. The primary immune response to $\mathrm{HBV}$ vaccine decreases with increasing age, especially after 40 years old as it declines to $90 \%$ [18]. Studies in Yemen have demonstrated that immunogenicity of $\mathrm{HBV}$ vaccine in healthy infants and children varies from $54.8 \%$ to $83.5 \%[13,19,20]$ as evident by antibodies to HB surface antigen (anti-HBs) response of $\geq 10 \mathrm{IU} / \mathrm{L}$ to pentavalent or a single vaccine. However, these studies were mainly conducted in urban $[13,20]$ or a mixed sample of both rural and urban areas [19]. A recent study conducted in Taiz found low routine vaccination coverage rate $(69.5 \%)$ among children aged $12-23$ months, with a highest coverage rate of $82.6 \%$ for HBV vaccine [21]. More than 130 million children are born each year worldwide and need to be immunized. Over 27 million children, living mainly in rural communities, are not reached by routine immunization services and significant variations in coverage rate are found between and within regions and countries [22].

In Yemen, health care facilities are mainly concentrated in urban centers and developed governorates leading to $80 \%$ health coverage in urban areas in comparison to only $25 \%$ coverage in the rural areas [14]. Our study assesses an outcome of these gaps by evaluating the coverage rate of $\mathrm{HBV}$ vaccine and the protective immune response to $H B V$ vaccine among children under five years old vaccinated with the three doses of HBV vaccine who live in rural areas around Taiz, Yemen.

\section{Materials and Methods}

2.1. Study Population. This cross-sectional study was conducted from January to December 2015 at four rural districts including 11 villages in Taiz governorate, Yemen (Table 1). These districts represent about one-third of rural districts in Taiz governorate and the 11 villages are located within about 60 kilometers from the city center of Taiz. Districts and villages selection was based on geographical location and population size per village drawn from the latest population census of 2004. The target population was children aged from 6 to 59 months of a total number of 1789 individuals in the
TABLE 1: Number and distribution of 6-59-month-old children study population among districts and villages of rural Taiz, Yemen.

\begin{tabular}{lcc}
\hline District & Villages & Number of children \\
\hline \multirow{2}{*}{ Sama } & Aldar & 60 \\
& Alhub & 31 \\
& Almanagl & 24 \\
\hline Total & 3 & 115 \\
\hline \multirow{2}{*}{ Al Ma'afer } & Alarida & 13 \\
& Alsheib & 21 \\
\hline Total & 2 & 34 \\
\hline \multirow{2}{*}{ Al Mawasit } & Almanhi & 13 \\
& Almarafed & 16 \\
\hline Total & Hagafer & 14 \\
\hline \multirow{3}{*}{ Almsrakh } & 3 & 43 \\
& Aldera & 10 \\
Total & Hugmah & 18 \\
\hline Grand total & Alkehaf & 7 \\
\hline
\end{tabular}

study area. All 228 children aged 6-59 months registered in the rural health units within the study area were enrolled in the study (Table 1). Information about vaccination status according to the last dose of HBV vaccine, sex, and age at the time of the study has been obtained through face to face interview with the children guardians. Ethical approval for this study was obtained from the ministry of public health and population in Yemen. Informed consent was obtained from the parent or guardian of the children enrolled in the study following explanation of the goal of the study.

2.2. Measurement of HBV Markers. Two milliliters of venous blood samples was collected from 228 children enrolled in the study based on the criteria listed above and sera were separated and frozen at $-20^{\circ} \mathrm{C}$ until testing. Natural immunity to $\mathrm{HBV}$ infection was first excluded by screening for total anti-HB core antibodies as previously described [13]. One child who had anti-HB core antibodies was excluded from study. Rest of the sera were then tested for anti-HBs using recombinant Hepatitis $\mathrm{B}$ virus surface antigen ( $\mathrm{rHBs} \mathrm{Ag}$ ) found in the sandwich ELISA AxSYM AUSAB kit following the manufacturer protocol (Abbott, Germany). Anti- HBs antibody concentration was expressed in international units per liter (IU/L). The protective immune response was defined as anti $\mathrm{HBs}$ antibodies level of $\geq 10$ IU/L $[23,24]$.

2.3. Statistical Analysis. The data was analyzed using version 17 of the Statistical Package of Social Science (SPSS) (SPSS Inc., Chicago, IL, USA). For the qualitative data (frequency and proportion), the Chi-Square test was used statistically to compare observed data with expected data. All differences were considered statistically significant when the Probability values $(P$ value $)$ were $<0.05$. Correlation coefficient and 
TABLE 2: The coverage rate of hepatitis B vaccine (HBV) according to gender.

\begin{tabular}{|c|c|c|c|c|c|c|}
\hline \multirow{2}{*}{ Status } & \multicolumn{2}{|c|}{ Males } & \multicolumn{2}{|c|}{ Females } & \multicolumn{2}{|c|}{ Total } \\
\hline & Number & $(\%)$ & Number & $(\%)$ & Number & $(\%)$ \\
\hline Vaccinated & 95 & $(88 \%)$ & 103 & $(86.6 \%)$ & 198 & $(87.2 \%)$ \\
\hline Nonvaccinated & 13 & $(12 \%)$ & 16 & $(13.4 \%)$ & 29 & $(12.8 \%)$ \\
\hline Total & 108 & $(100 \%)$ & 119 & $(100 \%)$ & 227 & $(100 \%)$ \\
\hline
\end{tabular}

TABLE 3: Gender-based Immune response to HBV vaccine among 6-59-month-old vaccinated children in rural areas of Taiz, Yemen.

\begin{tabular}{|c|c|c|c|c|c|c|}
\hline \multirow{2}{*}{ Anti-HBs titer (IU/L) } & \multicolumn{2}{|c|}{ Males } & \multicolumn{2}{|c|}{ Females } & \multicolumn{2}{|c|}{ Total } \\
\hline & Number & (\%) & Number & $(\%)$ & Number & (\%) \\
\hline$<10$ & 30 & $(31.6 \%)$ & 25 & $(24.3 \%)$ & 55 & $(27.8 \%)$ \\
\hline $10-100$ & 26 & $(27.4 \%)$ & 25 & $(24.3 \%)$ & 51 & $(25.8 \%)$ \\
\hline $101-999$ & 33 & $(34.7 \%)$ & 38 & $(36.9 \%)$ & 71 & $(35.9 \%)$ \\
\hline$\geq 1000$ & 6 & $(6.3 \%)$ & 15 & $(14.6 \%)$ & 21 & $(10.6 \%)$ \\
\hline Total & 95 & $(100 \%)$ & 103 & $(100 \%)$ & 198 & $(100 \%)$ \\
\hline
\end{tabular}

TABLE 4: Comparison of the geometric mean of protective Anti-HBs levels $(\geq 10 \mathrm{IU} / \mathrm{L})$ in $\mathrm{HBV}$ vaccinated children by age groups by oneway ANOVA.

\begin{tabular}{lcccc}
\hline Age (years) & No & $\begin{array}{c}\text { Anti-HBs geometric } \\
\text { mean }\end{array}$ & $F$ & $P$ value \\
\hline$<1$ & 27 & 189.3004 & & \\
1 to $<2$ & 49 & 60.0875 & 3.229 & 0.014 \\
2 to $<3$ & 29 & 99.9618 & & \\
3 to $<4$ & 28 & 81.4639 & & \\
4 to $<5$ & 65 & 21.2379 & \\
\hline Total & 198 & 56.1740 & \\
\hline
\end{tabular}

differences between anti-HBs levels were measured using the Spearman's and one way ANOVA tests of the SPSS package.

\section{Results}

A total of 227 children with mean age of $36.44 \pm 18.5$ SD months, 108 (47.6\%) males and 119 (52.4\%) females, were included in this study. One hundred and ninety-eight children were vaccinated (87.3\%) and 29 (12.8\%) unvaccinated indicating $87.3 \%$ coverage rate of $\mathrm{HBV}$ vaccine. $\mathrm{HBV}$ vaccine coverage was $88 \%$ and $86.6 \%$ for males and females, respectively (Table 2). In this study, $143(72.2 \%)$ of 198 children showed anti-HBs protective level of $\geq 10 \mathrm{IU} / \mathrm{L}$, while $55(27.8 \%)$ showed nonprotective anti-HBs titer levels of $<10 \mathrm{IU} / \mathrm{L}$. Protective anti-HBs levels were slightly higher in females $(75.7 \%)$ than males $(68.4 \%)$ (Table 3 ) but this difference was not statistically significant $(P=0.251)$. Anti-HBs antibody levels were then compared in various age groups $(<1$ year, 1 to $>2$ years, 2 to $<3$ years, 3 -to $<4$ years, and 4 to $<5$ years old). Protective responses to $\mathrm{HBV}$ vaccine as measured by levels of anti-HBs differed significantly between age groups $(P=0.014)$ (Table 4$)$ with $88.9 \%$ protective rate in infant children less than one year and $55.4 \%$ rate for children aged in the 4 - to $<5$-year-old age group (Figure 1). Anti-HBs levels were found to decrease with the increasing age (correlation

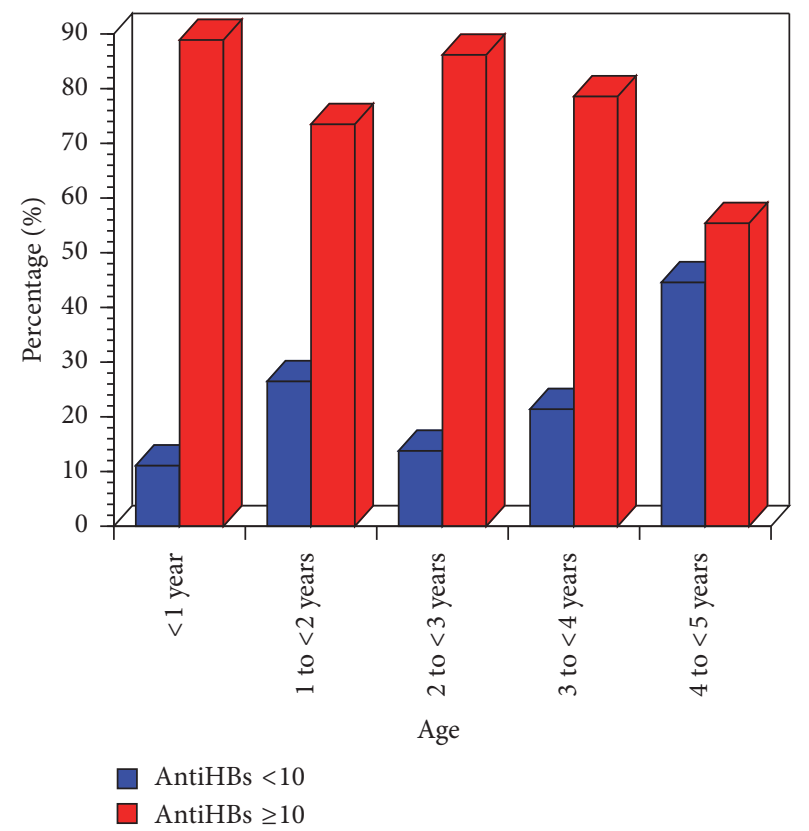

FIgURE 1: Comparison of anti-HBs antibody levels in vaccinated 659-month children according to age groups.

coefficient $=-0.306$ ) with the second year group response being less than the third and fourth year groups (Table 4) (Figure 1).

\section{Discussion}

This study showed relatively high HBV vaccination coverage rate of $87.3 \%$ in rural area around Taiz, Yemen. These finding are similar to our recent study conducted on malnourished children in Yemen [19] and higher than the 70\% rate reported from Sana'a city in 2011 [13]. This higher HBV vaccine coverage rate might be attributed to increased response to the ministry of public health and population awareness and 
educational programs and increased efficiency of vaccination campaigns. The national health status in Yemen has been in steady growth recently due to the concerted efforts to educate the public about the importance of immunization in the fight against infectious childhood diseases in minimizing mortality rate. However, our study showed lower coverage compared to endemic developed [25] and developing [26] countries, where $\mathrm{HBV}$ vaccine coverage rates among children ranged from 90 to $98 \%$.

The present study revealed $72.2 \%$ protective rate (anti$\mathrm{HBs} \geq 10 \mathrm{IU} / \mathrm{L}$ ) for vaccinated healthy children in rural areas of Taiz. This HBV vaccine seroprotective rate was higher than the rate reported in children $<1-10$ years old by Al Shamahy and coworkers in Sana'a 5 years ago [13]. However, it was lower than that reported by Sallam and coworkers from Sana'a in 2005 [20]. In the same study, however, Sallam and coworkers noted significantly lower HBV antibody level among children with low economic status. These variations in effectiveness of vaccine may be as a result of differences in socioeconomic status, health care program, and ethnic differences between populations. Lower levels of anti-HBs antibodies could also be related to existing problems with the cold chain of vaccines in rural areas that lead to decreased efficacy of the pentavalent vaccine. Lower responses to HBV vaccine in low socioeconomic areas have been reported in Taiwan [27] and significant correlation between nutritional status and the response to $\mathrm{HBV}$ vaccination has been reported in Senegal and Cameron [28]. In addition, Losonsky and coworkers reported association between low weight and poor weight gain in the first 6 months of life with decreased immunogenicity after three doses of HBV vaccine in the United States [29].

Our study also showed slightly higher protective rate of anti-HBs antibody in females $78(75.7 \%)$ compared to males (68.4\%). Similar gender-based HBV vaccine protective rates were reported in previous studies conducted in Yemen [19, 20] and in China [30]. This gender-based variation may be possibly due to the physiological and behavioural differences between the gender which plays important role in immune response [31, 32]. In particular, females mount higher innate and adaptive immune responses to pathogen challenge than males do. Fish and coworkers found constitutively higher levels of circulating $\mathrm{T}$ cells in females compared with males, which probably contribute to gender-differential nonspecific effects (NSE) of vaccines [33]. In addition, Klein and coworkers [34] reported more robust innate immune responses in females to the yellow fever vaccine as well as higher antibody responses in females to the influenza vaccine, combined measles mumps rubella (MMR) vaccine, and hepatitis $A$ and $B$ vaccines [34]. Moreover, mice studies showed that males generally produce more proinflammatory cytokines, such as IL- 6 and TNF, while females produce more of the antiinflammatory cytokines [35]. These data support the genderbased differences in response to $\mathrm{HBV}$ vaccination reported in this study.

This study showed significant differences and negative correlation in $\mathrm{HBV}$ vaccine protection rate between age groups $(<1-5$ years), with highest protective rate in the less than one year age group. The low correlation value was due to the weaker protective response of the one to $<2$ years old group compared to the older age group. This finding was supported by previous reports of declined HBV vaccine protective level with age in Yemen [13, 19]. Similar association between older age and lower level of HBV vaccine protection rate has been reported by studies conducted in Saudi Arabia [36], Europe [37], and China [38, 39]. A well-described agerelated modulation of the immune system is the decline of de novo generation of $\mathrm{T}$ and $\mathrm{B}$ cells. In addition, the accumulation of memory cells and loss of diversity in antigen specificities caused by a lifetime of exposure to pathogens have also been described [40].

Our study has been limited by sample size, geographic area, and difficulty to interpret associations. Additional studies with larger sample size and more representative areas are needed to verify the role of factors such as age, gender, race, site of injection, nutritional status, and vaccine brand on responses to HBV vaccine in Yemen.

\section{Conclusions}

This study showed good coverage and moderate protective rate against HBV in rural areas around Taiz. Further studies are recommended to provide better estimates of $\mathrm{HBV}$ vaccine coverage and rate of the vaccine protection among Yemeni children and to detect the factors that affect the vaccine protective rates. Such information is important for policy makers for planning strategies to improve these rates. The study also estimated proportion of vaccinated children in rural areas of Taiz, Yemen who should be considered for either revaccination or booster doses.

\section{Competing Interests}

The authors declare that they have no competing interests.

\section{Acknowledgments}

The authors are grateful to the Office of Health in Taiz governorate and WHO office in Yemen for financial support of this study and to participants who agreed to participate in the study. The authors owe thanks to Dr. Soliman Hassan, Dr. Ahmed Maret, and Dr. Nagmy Awn for facilitating access to the laboratory of the Military hospital, Sana'a. The authors are sincerely indebted to the doctors and nursing staff in Sabaa-July Health Center in Al-Shaoba area and the YemeniSwedish Hospital for their contribution to the successful completion of this study. Authors would also like to thank Dr. Hamdi Al Hakimi for assistance with statistical analysis.

\section{References}

[1] V. Chaudhary, R. Kumar, V. K. Agarwal, V. K. Joshi, and D. Sharma, "Evaluation of primary immunization coverage in an urban area of Bareilly city using cluster sampling technique," National Journal of Integrated Research in Medicine, vol. 1, no. 4, pp. 10-15, 2010.

[2] A. S. F. Lok and B. J. McMahon, "Chronic hepatitis B," Hepatology, vol. 45, no. 2, pp. 507-539, 2007. 
[3] A. Demirjian and O. Levy, "Safety and efficacy of neonatal vaccination," European Journal of Immunology, vol. 39, no. 1, pp. 36-46, 2009.

[4] B. Nath, J. Singh, S. Awasthi, V. Bhushan, V. Kumar, and S. Singh, "A study on determinants of immunization coverage among 1223 months old children in urban slums of Lucknow district, India," Indian Journal of Medical Sciences, vol. 61, no. 11, pp. 598606, 2007.

[5] WHO and UNICEF, Global Immunization Data, World Health Organization, Geneva, Switzerland, 2008, http://www.who.int/ immunization/newsroom/Global_Immunization_Data.pdf.

[6] E. A. Murad, S. M. Babiker, G. I. Gasim, D. A. Rayis, and I. Adam, "Epidemiology of hepatitis B and hepatitis $C$ virus infections in pregnant women in Sana'a, Yemen," BMC Pregnancy and Childbirth, vol. 13, no. 1, pp. 127-131, 2013.

[7] H. Al-Shamahy, "Prevalence of hepatitis B surface antigen and risk factors of HBV infection in a sample of healthy mothers and their infants in Sana'a, Yemen," Annals of Saudi Medicine, vol. 20, no. 5-6, pp. 464-466, 2000.

[8] M. A. Bajubair, A. A. Elrub, and G. Bather, "Hepatic viral infections in Yemen between 2000-2005," Saudi Medical Journal, vol. 29, no. 6, pp. 871-874, 2008.

[9] T. A. Sallam, Y. A. Rajaa, S. Bahaj et al., "Hepatitis B virus carrier rate, prevalence and susceptibility and impact of immunization program among households in the city of Taiz, Yemen," Vaccine, vol. 30, no. 37, pp. 5564-5568, 2012.

[10] J. Juszczyk, "Clinical course and consequences of hepatitis B infection," Vaccine, vol. 18, no. 1, pp. S23-S25, 2000.

[11] Y.-H. Ni, M.-H. Chang, L.-M. Huang et al., "Hepatitis B virus infection in children and adolescents in a hyperendemic area: 15 years after mass hepatitis B vaccination," Annals of Internal Medicine, vol. 135, no. 9, pp. 796-800, 2001.

[12] N. Yazigi and W. F. Balistreri, "Viral hepatitis," in Nelson Textbook of Pediatrics, R. M. Kliegman and W. W. E. Nelson, Eds., Elsevier, Oxford, UK, 2007.

[13] H. A. Al-Shamahy, S. H. Hanash, I. A. Rabbad, N. M. AlMadhaji, and S. M. Naser, "Hepatitis B vaccine coverage and the immune response in children under ten years old in Sana', Yemen," Sultan Qaboos University Medical Journal, vol. 11, no. 1, pp. 77-82, 2011.

[14] B. M. Al-Eryani, Child malnutrition in Yemen: the role of female education [M.S. thesis], Royal Tropical Institute (KIT), Amsterdam, the Netherlands, 2006.

[15] World Bank, Yemen Overview, 2015, http://www.worldbank.org/ en/country/yemen/overview.

[16] A. J. Roome, S. J. Walsh, M. L. Cartter, and J. L. Hadler, "Hepatitis B vaccine responsiveness in connecticut public safety personnel," JAMA, vol. 270, no. 24, pp. 2931-2934, 1993.

[17] M.-H. Chang, "Impact of hepatitis B vaccination on hepatitis $B$ disease and nucleic acid testing in high-prevalence populations," Journal of Clinical Virology, vol. 36, no. 1, pp. S45-S50, 2006.

[18] L.-C. Hsu, S.-R. Lin, H.-M. Hsu et al., "Ethnic differences in immune responses to hepatitis B vaccine," American Journal of Epidemiology, vol. 143, no. 7, pp. 718-724, 1996.

[19] F. Alsamei, A. Elagib, N. Al-Sonboli, F. Alkumaim, N. Alsayaad, and A. Aldobibi, "Evaluation of immune response to hepatitis B vaccine among malnourished children in Yemen," Yemeni Journal for Medical Sciences, vol. 9, no. 1, pp. 14-21, 2015.

[20] T. A. Sallam, H. M. Alghshm, A. A. Ablohom et al., "Immune response to hepatitis B vaccine among children in Yemen," Saudi Medical Journal, vol. 26, no. 2, pp. 281-284, 2005.
[21] N. A. Al-Rabeei, A. M. Dallak, and A. A. Al-Fosail, "Immunization coverage among children in Al-Taizyah district, Taiz governorate, Yemen," Indian Journal of Community Health, vol. 26, no. 4, pp. 343-348, 2014.

[22] UNIECF, Multiple Indicator Cluster Survey 3, UNICEF, New York, NY, USA, 2006, http://mics.unicef.org/surveys.

[23] A. D. Jack, A. J. Hall, N. Maine, M. Mendy, and H. C. Whittle, "What level of hepatitis B antibody is protective?" Journal of Infectious Diseases, vol. 179, no. 2, pp. 489-492, 1999.

[24] "Hepatitis B," in Immunisation Against Infectious Disease: 'The Green Book', D. Salisbury, M. Ramsay, and K. Noakes, Eds., pp. 161-184, The Stationery Office, London, UK, 2006, http://www.dh.gov.uk/en/Publichealth/Healthprotection.

[25] Centers for Disease Control (CDC), "A comprehensive immunization strategy to eliminate transmission of hepatitis $\mathrm{B}$ virus infection in the United States: recommendations of the Advisory Committee on Immunization Practices (ACIP). Part II: immunization of adults," Morbidity and Mortality Weekly Report, vol. 55, p. 16, 2006.

[26] A. M. N. Costa, G. L. Italien, M. E. Nita, and E. S. A. Araujo, "Cost-effectiveness of entecavir versus lamivudine for the suppression of viral replication in chronic hepatitis B patients in Brazil," Brazilian Journal of Infectious Diseases, vol. 12, no. 5, pp. 368-373, 2008.

[27] L.-Y. Wang, C.-T. Hu, T.-Y. Ho, and H. H. Lin, "Geographic and ethnic variations of long-term efficacy and immunogenicity of hepatitis B vaccination in Hualien, a HBV hyperendemic area," Vaccine, vol. 24, no. 20, pp. 4427-4432, 2006.

[28] M.-A. Rey-Cuille, A. Seck, R. Njouom et al., "Low immune response to hepatitis B vaccine among children in Dakar, Senegal," PLoS ONE, vol. 7, no. 5, Article ID e38153, 2012.

[29] G. A. Losonsky, S. S. Wasserman, I. Stephens et al., "Hepatitis $B$ vaccination of premature infants: a reassessment of current recommendations for delayed immunization," Pediatrics, vol. 103, no. 2, 1999.

[30] Y. Guo and C.-Y. Hui, "Pilot-scale production and quality control of multiepitope hepatitis B virus DNA vaccine," Journal of Southern Medical University, vol. 29, no. 1, pp. 118-120, 2009.

[31] S. M. Merkel, S. Alexander, E. Zufall, J. D. Oliver, and Y. M. Huet-Hudson, "Essential role for estrogen in protection against Vibrio vulnificus-induced endotoxic shock," Infection and Immunity, vol. 69, no. 10, pp. 6119-6122, 2001.

[32] V. Kahlke, C. Dohm, T. Mees, K. Brötzmann, S. Schreiber, and J. Schröder, "Early interleukin-10 treatment improves survival and enhances immune function only in males after hemorrhage and subsequent sepsis," Shock, vol. 18, no. 1, pp. 24-28, 2002.

[33] E. N. Fish, "The X-files in immunity: sex-based differences predispose immune responses," Nature Reviews Immunology, vol. 8, no. 9, pp. 737-744, 2008.

[34] S. L. Klein, A. Jedlicka, and A. Pekosz, "The Xs and Y of immune responses to viral vaccines," The Lancet Infectious Diseases, vol. 10, no. 5, pp. 338-349, 2010.

[35] I. Marriott, K. L. Bost, and Y. M. Huet-Hudson, "Sexual dimorphism in expression of receptors for bacterial lipopolysaccharides in murine macrophages: a possible mechanism for genderbased differences in endotoxic shock susceptibility," Journal of Reproductive Immunology, vol. 71, no. 1, pp. 12-27, 2006.

[36] T. A. Madani, "Trend in incidence of hepatitis B virus infection during a decade of universal childhood hepatitis B vaccination in Saudi Arabia," Transactions of the Royal Society of Tropical Medicine and Hygiene, vol. 101, no. 3, pp. 278-283, 2007. 
[37] A. Nardone, C. G. Anastassopoulou, H. Theeten et al., "A comparison of hepatitis B seroepidemiology in ten European countries," Epidemiology and Infection, vol. 137, no. 7, pp. 961969, 2009.

[38] Y.-H. Zhou, C. Wu, and H. Zhuang, "Vaccination against hepatitis B: the Chinese experience," Chinese Medical Journal, vol. 122, no. 1, pp. 98-102, 2009.

[39] F. He, Y.-J. Ma, T.-Y. Zhou et al., "The serum anti-HBs level among children who received routine Hepatitis B vaccination during infancy in Mianyang City, China: a cross-sectional study," Viral Immunology, vol. 29, no. 1, pp. 40-48, 2016.

[40] P. Sansoni, R. Vescovini, F. Fagnoni et al., "The immune system in extreme longevity," Experimental Gerontology, vol. 43, no. 2, pp. 61-65, 2008. 


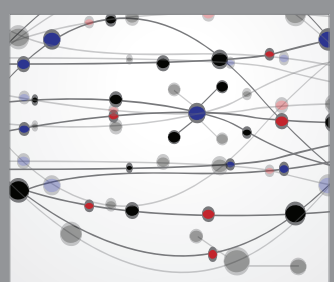

The Scientific World Journal
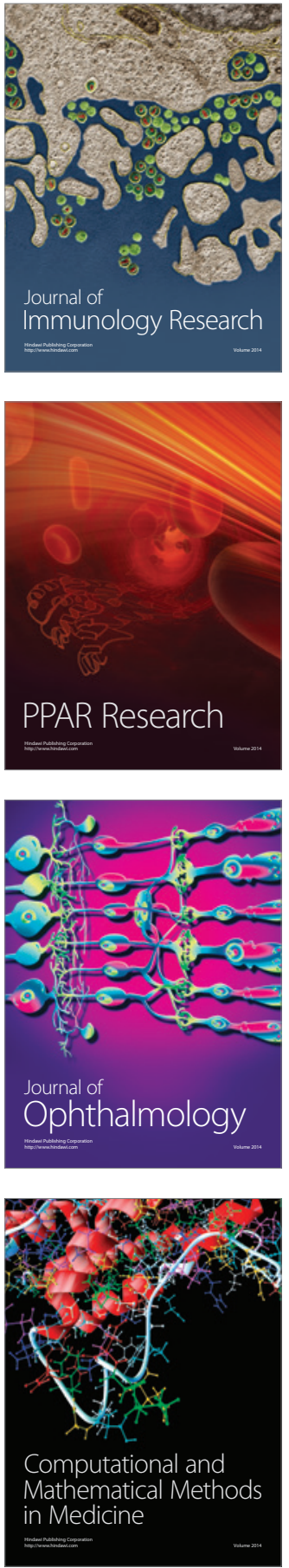

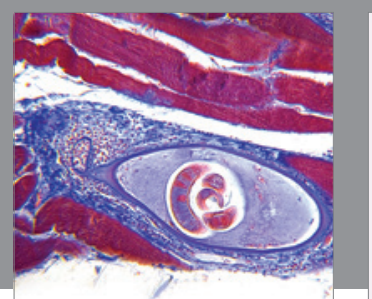

Gastroenterology Research and Practice
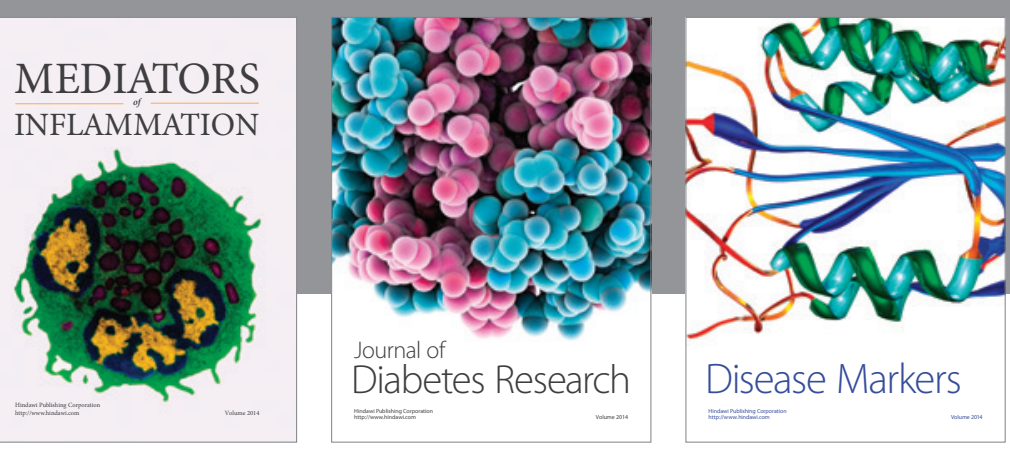

Disease Markers

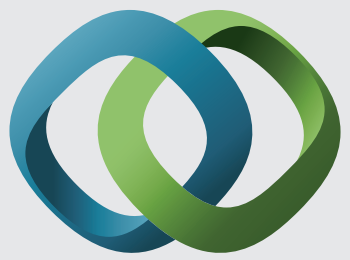

\section{Hindawi}

Submit your manuscripts at

https://www.hindawi.com
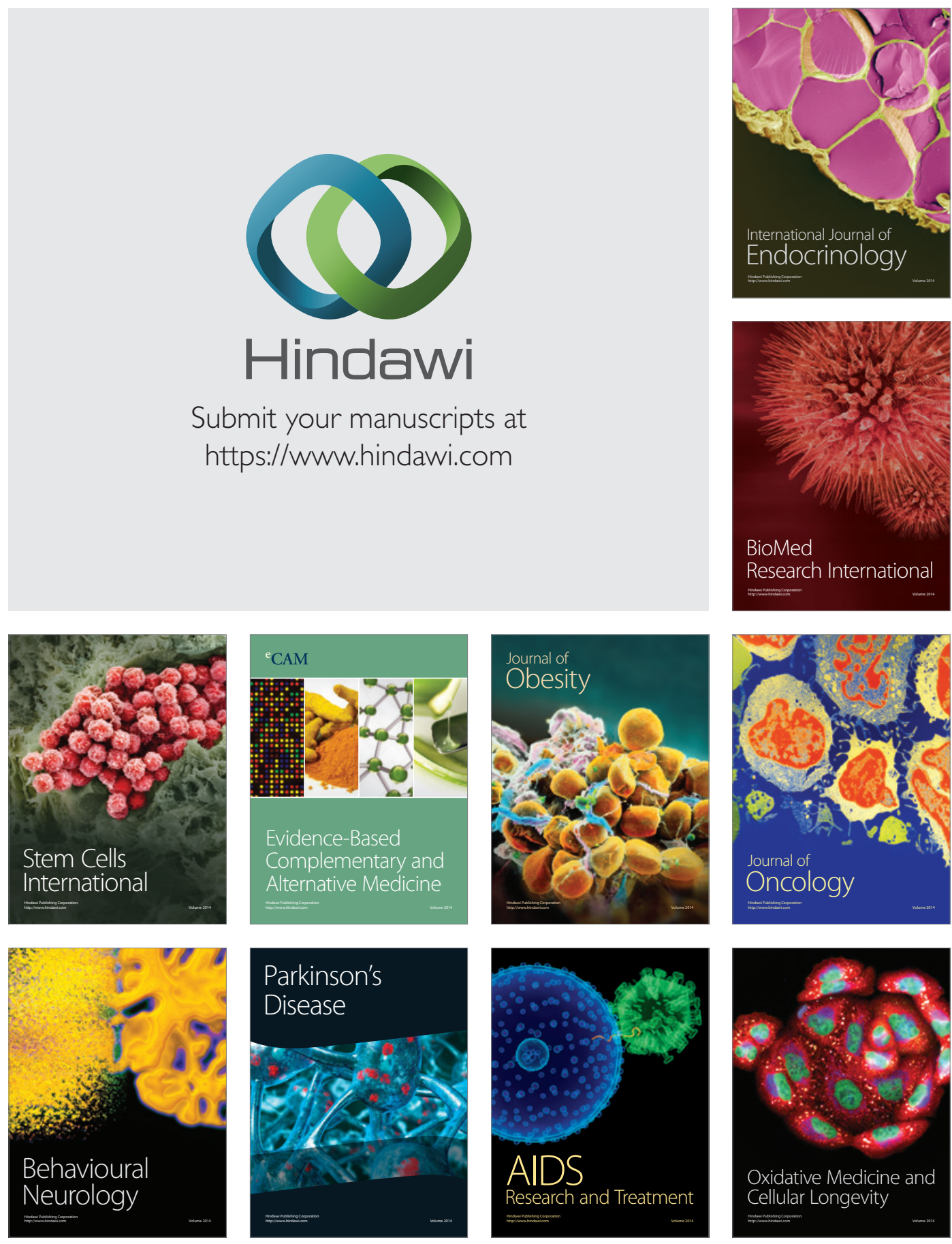